Endocrinol. Japon. 1961, 8 (1), 1 8

\title{
ON THE FUNGTIONAL CORRELATION BETWEEN SALIVARY GLANDS AND OTHER ENDOGRINE ORGANS III. THE RELATIONSHIP BETWEEN IODINE METABOLISM BY THE THYROID GLAND AND THE WEIGHT OF THE SALIVARY GLANDS OF RATS (STUDIES ON THE PHYSIOLOGICAL CHEMISTRY OF THE SALIVARY GLANDS L*)
}

\author{
YOSOJI ITO, JUN KAWADA AND MUNETSUGU KURATA \\ Department of Physiological Chemistry, Faculty of Pharmaceutical \\ Sciences, University of Tokyo, Tokyo
}

\begin{abstract}
Although it has been established that the salivary glands, especially the submaxillary glands of rats makedly decreased in weight by adding some antithyroid drugs to drinking water, (Ito and Kawada, 1959; Ito et al., 1960), the relation between the change in thyroidal iodine metabolism and the change in weight of salivary glands of animals treated with these drugs has remained unexamined. The examination of this relation might open a way to the question, whether these anithyroid drugs act on the salivary glands directly or whether they act through the change of the function of the thyroid gland. The organic binding of iodine by the thyroid gland is blocked by the single injection or the prolonged administration of iodide (Wolff and Chaikoff, 1948a, b; Raben, 1949; Galton and Pitt-Rivers, 1959), but the effect of iodide on the salivary glands is still unknown. On the other hand, circulating iodide is concentrated by the salivary and mammary glands in some animals, but the rat shows no salivary concentration of iodide (Johnson and Albert, 1951 ; Brown-Grant, 1956; Flletcher et al., 1956; Freinkel and Ingbar, 1956; Halmi et al., 1956). This paper is concerned with the effect of some antithyroid drugs on the iodide concentration in the salivary glands and other organs and with the examination of the relation between the change in the weight of salivary glands and the change in thyroidal iodine metabolism induced by the administration of these antithyroid substances or iodide.
\end{abstract}

\section{MATERIALS AND METHODS}

Animals Adult male rats of a Wistar strain were used in these studies. The antithyroid drugs or iodide were administered to the animals from 8 weeks old. They were sacrificed at 2 weeks and 7 weeks in the antithyroid group and at 3 weeks in the iodide group respectively starting after the administration. Commercial compressed diet, CLEA-pellet (CE-2), and water were given ad libitum. Each group consisted of 5 to 8 animals as indicated in the following tables.

Received for publication October 20, 1960.

* XLIX: Ito, Y. and M. Shinoda (1960). Endocrinol. Japon. 7, 336. 
Administration of antithyroid drugs and iodide As antithyroid drugs, the following substances were added to drinking water for 2 or 7 weeks in the concentrations indicated; $\mathrm{KClO}_{4} 0.5 \%$, 1-methyl-2-mercaptoimidazole (MMI) $0.1 \%$, thiouracil (TU) $0.1 \%$ and 6 -methyl-thiouracil (MTU) $0.1 \%$. KI was administered in $0.01 \%$ solution.

Study with radioiodine Ten $\mu \mathrm{C}$ of ${ }^{131} \mathrm{I}\left(\mathrm{Na}^{131} \mathrm{I}\right)$ containing $1.5 \times 10^{-3} \mu \mathrm{g}^{127} \mathrm{I}\left(\mathrm{Na}^{127} \mathrm{I}\right)$ as carrier was injected intraperitoneally into each animal. Animals of the antithyroid groups given ${ }^{131} I$ were sacrificed $6 \mathrm{hrs}$. thereafter and those of the KI groups were sacrificed $24 \mathrm{hrs}$. after being given ${ }^{131} \mathrm{I}$. This was done by exsanguination from the carotid.

Total plasma ${ }^{131} \mathrm{I}$ and $\mathrm{PB}^{131} \mathrm{I}$ were determined as follows. A $1.0 \mathrm{ml}$ aliquot of the plasma diluted with $0.1 \% \mathrm{NaI}$ to a 10 -fold dilution was mixed with $0.5 \mathrm{ml}$ of $N \mathrm{NaOH}$ in order to ascertain the total plasma ${ }^{131} \mathrm{I}$. This sample was evaporated by the infra-red lamp in a cupped planchet and the radipactivity was measured in a G-M counter.

For the determination of plasma $\mathrm{PB}^{131} \mathrm{I}$, a $1.0 \mathrm{ml}$ aliquot of the diluted plasma was mixed with $1.0 \mathrm{ml}$ of $0.1 \% \mathrm{NaI}$ and added $1.0 \mathrm{ml}$ of $5 \%$ TCA. After centrifugation, the precipitate was dissolved in $1.5 \mathrm{ml}$ of $N \mathrm{NaOH}$ and transfered to cupped planchet. The counting sample was made and the radioactivity was measured in the usual manner.

The radioactivity of TCA soluble fraction and TCA insoluble fraction of the thyroid gland were measured as a criterion of thyroidal iodine metabolism. After the thyroid was removed and quickly weighed, it was homogenized in a Potter-Elvehjem glass-homogenizer containing $1.0 \mathrm{ml}$ of $0.1 \% \mathrm{NaI}$. After the test-tube and the pestle of the apparatus were washed with $3.0 \mathrm{ml}$ of $0.1 \% \mathrm{NaI}, 2.0 \mathrm{ml}$ of $10 \%$ TGA was added to the homogenate. Centrifugation completed, the supernatant was transfered to a test-tube. The precipitate was washed with $1.0 \mathrm{ml}$ of $0.1 \% \mathrm{NaI}$ and $1.0 \mathrm{ml}$ of $5 \%$ TCA. The washings were added to the supernatant until exactly $10 \mathrm{ml}$ solution with dist. $\mathrm{H}_{2} \mathrm{O}$. One $\mathrm{ml}$ of this TCA soluble fraction of the thyroid was pipetted into the cupped planchet and $0.5 \mathrm{ml}$ of $1 \% \mathrm{AgNO}_{3}$ was added. The mixture was evaporated and radioactivity was measured in a G-M counter. One $\mathrm{ml}$ of $N \mathrm{NaOH}$ was added to the precipitate and the soluble protein containing $\mathrm{PB}^{131} \mathrm{I}$ was dissolved. After centrifugation the precipitate was again dissolved in $1.0 \mathrm{ml}$ of $\mathrm{N} \mathrm{NaOH}$. The 1st and the 2nd supernatant were gathered and made to be a $10 \mathrm{mI}$ solution with dist. $\mathrm{H}_{2} \mathrm{O}$. The counting sample for the TCA insoluble fraction was prepared from this solution in the usual manner and the radioactivity was measured.

For the determination of the concentration of circulating iodide by some organs, except the thyroid gland, the radioactivity of salivary glands, thymus, liver and stomach was measured in a scintillation counter.

In all these measurements the standard counting samles were made under the same conditions as before, and the conventional corrections were applied for each sample.

\section{RESULTS AND DISCUSSION}

\section{The effect of antithyroid drugs on the iodide concentration by the salivary glands and other organs}

Table 1 shows the iodide concentration, as a ratio of ${ }^{131} \mathrm{I}$ in $100 \mathrm{mg}$ tissue/131 I in $0.1 \mathrm{ml}$ plasma, by the salivary glands (submaxillary, parotid and sublingual glands), thymus, liver, and stomach of the animals to which TU, MTU, MMI and $\mathrm{KClO}_{4}$ were given. No significant differences were recognized among the concentration in these portion of the salivary glands and these values were as much as those observed in the thymus or the liver. This finding coincides with the observations of many other authors' and it seems that the physiologically significant concentration of iodide does not occur in the salivary glands of rats. The con- 
Table 1. Effect of antithyroid drugs on the iodide concentration by the salivary glands and other organs $\left({ }^{131} \mathrm{l}\right.$ in $100 \mathrm{mg}$ tissue $/{ }^{131} \mathrm{I}$ in $0.1 \mathrm{ml}$ plasma) I. Effect of $\mathrm{KClO}_{4}$ or $\mathrm{MMI}$

Administration for 2 weeks

\begin{tabular}{|c|c|c|c|c|c|c|c|}
\hline & \multirow{2}{*}{$\begin{array}{l}\text { No. of } \\
\text { animals }\end{array}$} & \multicolumn{3}{|c|}{ Salivary glands } & \multirow{2}{*}{ Thymus } & \multirow{2}{*}{ Liver } & \multirow{2}{*}{ Stomach } \\
\hline & & Submaxillary & Sublingual & Parotid & & & \\
\hline Control & 6 & $2.6 \pm 0.03 *$ & $2.4 \pm 0.09$ & $2.6 \pm 0.11$ & $1.6 \pm 0.01$ & $1.5 \pm 0.01$ & $8.8 \pm 1.20$ \\
\hline $\mathrm{KClO}_{4}$ & 6 & $2.9 \pm 0.15$ & $2.9 \pm 0.06$ & $3.2 \pm 0.10$ & $1.8 \pm 0.08$ & $1.8 \pm 0.01$ & $5.0 \pm 0.59$ \\
\hline MMI & 6 & $2.5 \pm 0.18$ & $2.3 \pm 0.04$ & $2.7 \pm 0.10$ & $1.8 \pm 0.09$ & $1.4 \pm 0.06$ & $11.8 \pm 1.62$ \\
\hline
\end{tabular}

Administration for 7 weeks

\begin{tabular}{|c|c|c|c|c|c|c|c|}
\hline & \multirow{2}{*}{$\begin{array}{l}\text { No. of } \\
\text { anımals }\end{array}$} & \multicolumn{3}{|c|}{ Salivary glands } & \multirow{2}{*}{ Thymus } & \multirow{2}{*}{ Liver } & \multirow{2}{*}{ Stomach } \\
\hline & & Submaxillary & Sublingual & Paratid & & & \\
\hline Control & 5 & $3.1 \pm 0.15$ & $3.1 \pm 0.48$ & $3.5 \pm 0.06$ & $2.3 \pm 0.33$ & $3.7 \pm 0.63$ & $21.0 \pm 5.62$ \\
\hline $\mathrm{KClO}_{4}$ & 7 & $3.0 \pm 0.21$ & $2.7 \pm 0.15$ & $3.8 \pm 0.55$ & $2.1 \pm 0.17$ & $2.9 \pm 0.12$ & $15.3 \pm 3.16$ \\
\hline MMI & 7 & $4.0 \pm 0.30$ & $3.2 \pm 0.12$ & $3.8 \pm 0.10$ & $3.4 \pm 0.28$ & $2.4 \pm 0.18$ & $18.8 \pm 2.00$ \\
\hline
\end{tabular}

II. Effect of TU or MTU

Administration for 2 weeks

\begin{tabular}{|c|c|c|c|c|c|c|c|}
\hline & \multirow{2}{*}{$\begin{array}{l}\text { No. of } \\
\text { animals }\end{array}$} & \multicolumn{3}{|c|}{ Salivary glands } & \multirow{2}{*}{ Thymus } & \multirow{2}{*}{ Liver } & \multirow{2}{*}{ Stomach } \\
\hline & & Submaxillary & Sublingual & Parotid & & & \\
\hline Control & 7 & $2.6 \pm 0.04$ & $2.4 \pm 0.12$ & $2.4 \pm 0.15$ & $2.7 \pm 0.34$ & $1.7 \pm 0.02$ & $17.1 \pm 1.99$ \\
\hline TU & 8 & $2.8 \pm 0.22$ & $2.3 \pm 0.21$ & $2.9 \pm 0.23$ & $1.8 \pm 0.24$ & $2.4 \pm 0.14$ & $13.5 \pm 2.66$ \\
\hline MTU & 7 & $2.8 \pm 0.19$ & $2.4 \pm 0.11$ & $3.5 \pm 0.34$ & $3.5 \pm 0.34$ & $3.1 \pm 0.23$ & $19.5 \pm 1.28$ \\
\hline
\end{tabular}

Adminıstration for 7 weeks

\begin{tabular}{|c|c|c|c|c|c|c|c|}
\hline & \multirow{2}{*}{$\begin{array}{l}\text { No. of } \\
\text { animals }\end{array}$} & \multicolumn{3}{|c|}{ Salivary glands } & \multirow{2}{*}{ Thymus } & \multirow{2}{*}{ Liver } & \multirow{2}{*}{ Stomach } \\
\hline & & Submaxillary & Sublingual & Parotid & & & \\
\hline Control & 7 & $1.8 \pm 0.21$ & $1.8 \pm 0.34$ & $2.4 \pm 0.28$ & $1.8 \pm 0.36$ & $1.7 \pm 0.46$ & $9.1 \pm 0.70$ \\
\hline TU & 8 & $2.0 \pm 0.20$ & $1.7 \pm 0.14$ & $3.3 \pm 0.74$ & $2.5 \pm 0.39$ & $2.2 \pm 0.23$ & $7.3 \pm 2.16$ \\
\hline MTU & 8 & $2.9 \pm 0.27$ & $2.2 \pm 0.10$ & $3.2 \pm 0.39$ & $2.1 \pm 0.10$ & $1.5 \pm 0.08$ & $19.1 \pm 3.65$ \\
\hline
\end{tabular}

* Mean \pm Standard error

centration by the salivary glands might be regarded as simple diffusion and was not influenced by the administration of the anithyroid drugs. The iodide concentration by the stomach was several times higher than by the other organs. This trapping seems to be related to the gastric secretion of iodine. The antithyroid drugs also showed no effect upon the concentration.

The relation between thyroidal iodine metabolism and the change in the weight of salivary glands

The results of $\mathrm{KClO}_{4}$ or MMI administration are summarized in Table 2. In the group of 2 weeks treatment, the decrease in weight of the submaxillary glands 
was marked by the admınıstration or MINII, accompanıed with evident hyperplasia of the thyroid gland and disturbance of thyroidal iodine metabolism; the thyroidal iodine uptake and the organic binding of indide were depressed to about $1 / 3$ or $1 / 5$ of the normal control. On the other hand, rats which were given $\mathrm{KClO}_{4}$ showed no appreciable change in the weight of the submaxillary glands in spite of marked suppression of iodine metabolism by the thyroid gland as observed in MMI administration. In both groups, plasma $\mathrm{PB}^{131} \mathrm{I}$ showed no difference as compared with the normal control group.

In the group of 7 weeks treatment, the radio-iodide activities in thyroid gland and plasma were higher than those in 2 weeks treatment probably due to the decrease in environmental temperature as shown in Figure 1. Although, the tempera-

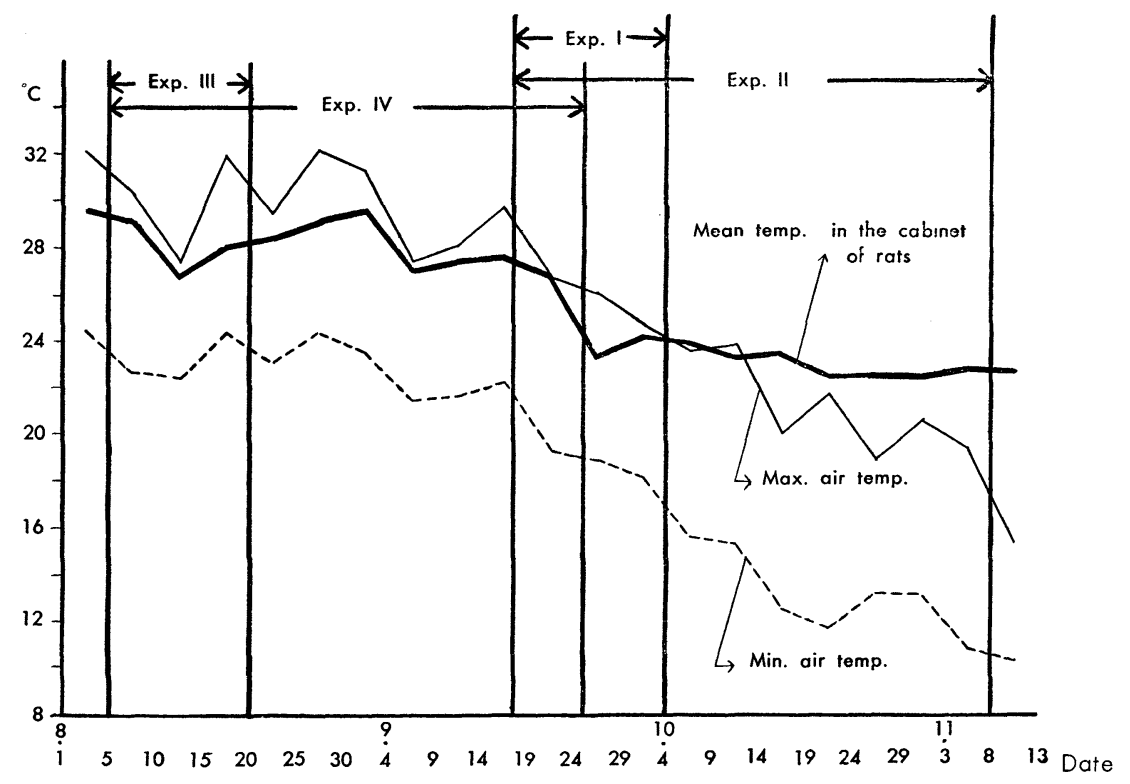

Fig. 1. Change of the environmental temperature during a series of experiments

ture in the cabinet of the animals was maintained almost constant level, about $23^{\circ} \mathrm{C} \sim 25^{\circ} \mathrm{C}$, the intrinsic rhythm of thyroidal function to the seasonable change might be involved. Rats administered with MMI showed high inhibition of the uptake and organic binding of iodide in the thyroid gland and resulted in marked weight loss of the submaxillary glands. Prolonged treatment of rats with $\mathrm{KClO}_{4}$, on the other hand, showed a slight decrease in the weight of the submaxillary glands. The uptake and organic binding in the thyroid gland reached to only about $2 / 3$ of the normal.

Table 3 summarized the effect of TU and MTU administration. In the previous paper, the authors could not observe the effect of MTU on the weight of the salivary glands (Ito et al., 1960), but significant weight loss of the submaxillary glands by MTU was shown in this experiment. This might be explained by the 


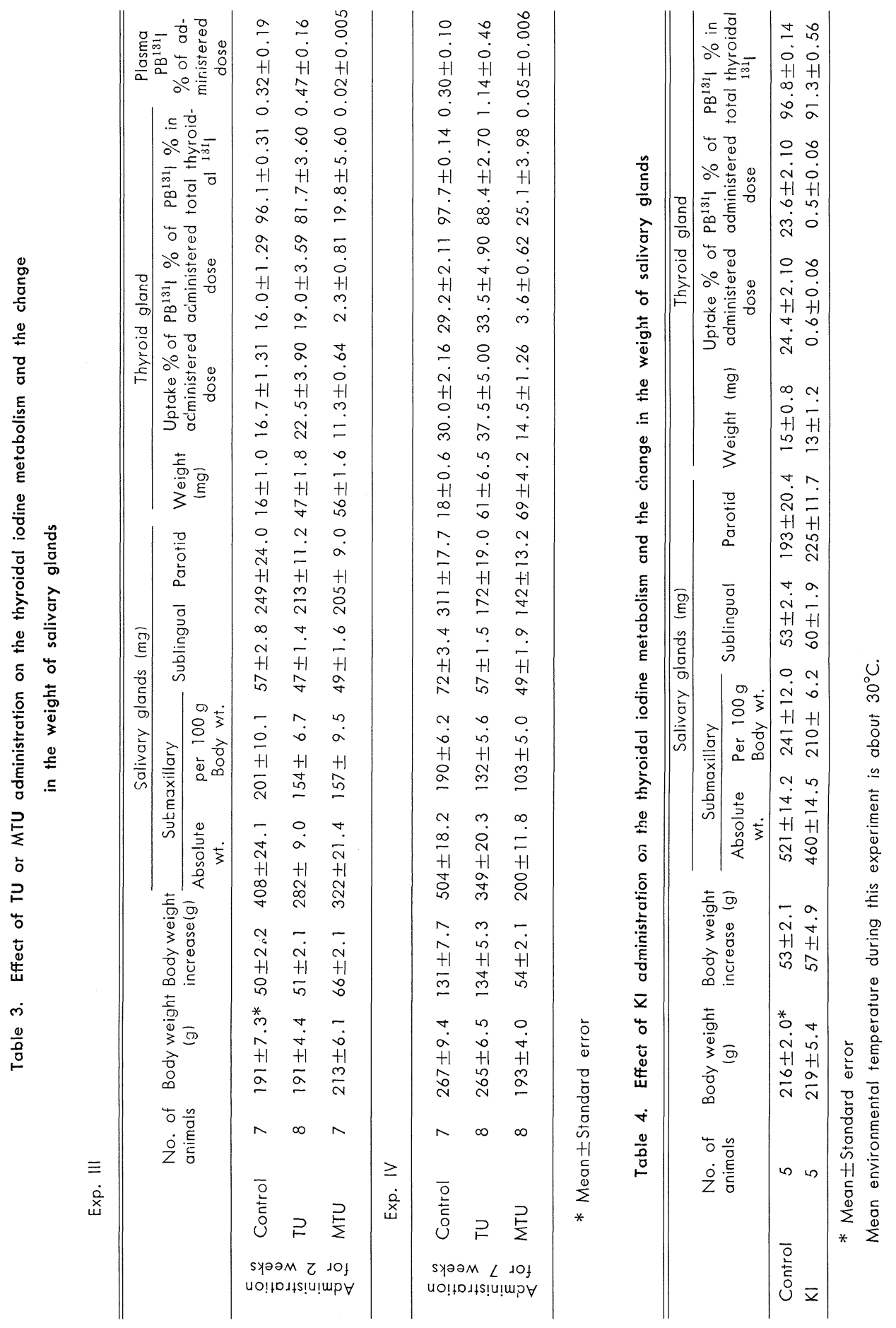


difference of the strain of rats and of their age at the time of sacrifice which was 2 weeks younger than the animal previously employed. The organic binding of iodide in the thyroid gland was strongly inhibited and plasma $\mathrm{PB}^{131}$ I level was also low in these animals both in the group for 2 weeks and 7 weeks administration of MTU. But, in the TU administered group, an increased organic binding in the thyroid and a higher plasma $\mathrm{PB}^{131}$ I level were observed as compared with the control notwithstanding the evident goiter formation and the marked atrophy of the submaxillary glands. This contradictory result is probably explained as follows; in this experiment, a diet is removed from the day before of sacrifice, though drinking water is given ad libitum during fasting. Since drinking water is not usually taken when the diet is removed, an antithyroid drug dissolved in drinking water is mainly ingested during the night before 2 days of exsanguination. Hence, at least $30 \mathrm{hrs}$. elapse after ingestion of an antithyroid drug until the sacrifice of animals. Within this period, the inhibition of thyroidal iodide metabolism by an antithyroid drug possessing short biological half-life would be recovered.

Maloof and Soodak (1957) reported the temporary effect of TU on the inhibition of iodide metabolism in the thyroid gland and TU's own metabolism by labelling it as " ${ }^{35} \mathrm{~S}$ ". Considering these results, the effect of TU on the thyroid gland seems to recover within $24 \mathrm{hrs}$. after administration. The time of sacrifice of the animals in the authors' experiment might fall into this recovering phase.

Three weeks treatment of rats with KI showed a slight decrease in the weight of the submaxillary glands, the uptake of iodide by the thyroid gland was only $0.6 \%$ against the control, about $24 \%$ of the administered dose, but the organic binding showed over $90 \%$ in both groups as summarized in Table 4 . These results coincide with those reported by Galton and Pitt-Rivers (1959) considering the period of KI administration, and the time of sacrifice of the animals following ${ }^{131}$ I injection. Assuming that the quantity of stable iodide was enough in the thyroid gland in this treatment, although the estimation of the content of ${ }^{127} \mathrm{I}$ is not carried out, it seems to be probable that the appreciable suppression on the function of the thyroid gland was not produced in spite of the apparent depression of the uptake of iodide.

In view of these results, the change in the weight of the salivary glands especially in the submaxillary gland is not always related to the depression of the iodine metabolism in the thyroid gland in this experimental condition. The doses of the drugs used must be further examined, but practically it is difficult to find out the appropriate equivalent doses of antithyroid drugs necessary to cause the same degree of thyroid disfunction. In this experiment, it is hard to conclude, that the effect of antithyroid drugs on the salivary glands is entirely due to the hypofunction of the thyroid gland.

\section{SUMMARY}

Observations have been made following the administration of $\mathrm{KClO}_{4}$, MMI TU and MTU for 2 or 7 weeks and KI for 3 weeks in drinking water to adult male rats and relation between the change in the weight of the salivary glands and the iodine metabolism has been examined using radio-iodine. The results are 
as follows :

1) The inhibition of iodine metabolism by the thyroid gland did not always result in the decrease in the weight of the salivary glands. There seems to be little evidence of the direct relationship between the function of the thyroid gland and the salivary glands from this experiment.

2) The significant iodide concentration by the salivary glands was not observed in the normal animals, and also the antithyroid drugs employed had no influence upon the concentration.

\section{REFERENCIES}

Brown-Grant, K. (1956). J. Physiol. 131, 58.

Flletcher, K., A. J. Honour and E. N. Rowlands (1956). Biochem. J. 63, 194.

Freinkel, N. and S. H. Ingbar (1956). Endocrinology 58, 51.

Galton, V.A. and R. Pitt-Rivers (1959). Ibid. 64, 835.

Halmi, N. S., R. G. Stuelke and M. D. Schnell (1956). Ibid. 58, 634.

Ito, Y. and J. Kawada (1959). Endocrinol. Japon. 6, 253.

Ito, Y., J. Kawada and M. Kurata (1960). Ibid. 7, 157.

Johnson, H. W. and A. Albert (1951). Endocrinology 41, 669.

Maloof, F. and M. Soodak (1957). Ibid. 61, 555.

Raben, M. S. (1949). Ibi.d. 45, 296.

Wolff, J. and I. L. Chaikoff (1948a). J. Biol. Chem. 172, 855.

Wolff, J. and I. L. Chaikoff (1948b). Ibid. 174, 555. 